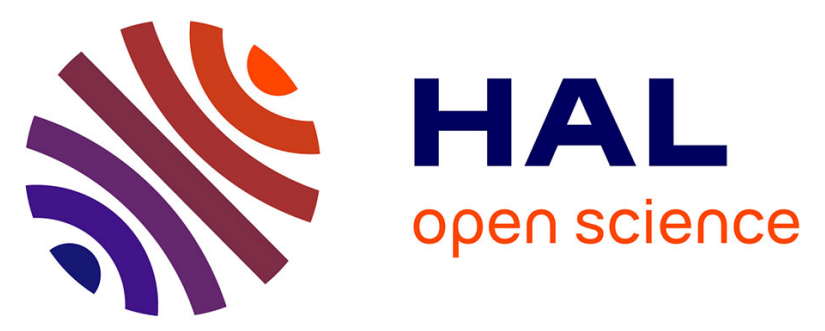

\title{
Modelling the HDO cycle of the Martian atmosphere with the LMD Global Climate Model
}

Margaux Vals, Loïc Rossi, Franck Montmessin, Francois Forget, Ehouarn Millour, Francisco Gonzalez-Galindo, Franck Lefèvre, Jean-Yves Chaufray

\section{To cite this version:}

Margaux Vals, Loïc Rossi, Franck Montmessin, Francois Forget, Ehouarn Millour, et al.. Modelling the HDO cycle of the Martian atmosphere with the LMD Global Climate Model. European Planetary Science Congress. EPSC 2021, Sep 2021, Virtual Meeting, France. 10.5194/epsc2021-296 . insu03318373

\section{HAL Id: insu-03318373}

https://hal-insu.archives-ouvertes.fr/insu-03318373

Submitted on 9 Aug 2021

HAL is a multi-disciplinary open access archive for the deposit and dissemination of scientific research documents, whether they are published or not. The documents may come from teaching and research institutions in France or abroad, or from public or private research centers.
L'archive ouverte pluridisciplinaire HAL, est destinée au dépôt et à la diffusion de documents scientifiques de niveau recherche, publiés ou non, émanant des établissements d'enseignement et de recherche français ou étrangers, des laboratoires publics ou privés. 


\title{
Modelling the HDO cycle of the Martian atmosphere with the LMD Global Climate Model
}

\author{
Margaux Vals ${ }^{1}$, Loïc Rossi ${ }^{1}$, Franck Montmessin ${ }^{1}$, François Forget ${ }^{2}$, Ehouarn Millour ${ }^{2}$, Francisco \\ Gonzalez-Galindo ${ }^{3}$, Franck Lefèvre ${ }^{1}$, and Jean-Yves Chaufray ${ }^{1}$ \\ ${ }^{1}$ CNRS, Laboratoire ATmosphères, Milieux, Observations Spatiales, Paris, Guyancourt, France (margaux.vals@latmos.ipsl.fr) \\ ${ }^{2}$ CNRS, Laboratoire de Météorologie Dynamique, Paris, France (Francois.Forget@Imd.jussieu.fr) \\ ${ }^{3}$ Instituto de Astrofísica de Andalucía-CSIC, Granada, Spain (ggalindo@iaa.es)
}

\section{Introduction}

The $\mathrm{D} / \mathrm{H}$ ratio observed in a planetary atmosphere is a proxy for the ratio of the current water reservoir over the initial water reservoir of the planet. The current $\mathrm{D} / \mathrm{H}$ ratio measured in the Martian atmosphere is at least five that of the Vienna Standard Mean Ocean Water (SMOW) (Owen et al. 1988, Encrenaz et al. 2018, Krasnopolsky 2015, Villanueva et al. 2015). This high value of the martian $\mathrm{D} / \mathrm{H}$ ratio, derived from the $\mathrm{HDO} / \mathrm{H}_{2} \mathrm{O}$ abundance ratio, is a precious indicator of the large escape of water from the martian atmosphere over time. Apart from the mass difference between both isotopes, the differential escape of $\mathrm{H}$ and $\mathrm{D}$ comes from the preferential photolysis of $\mathrm{H}_{2} \mathrm{O}$ over HDO (Cheng et al. 1999) and the Vapor Pressure Isotope Effect (VPIE) that produces an isotopic fractionation at condensation (Krasnopolsky, 2000, Bertaux et al. 2001, Fouchet et al. 2000).

\section{Modelling the HDO cycle}

Rossi et al. 2021 have implemented the HDO cycle, adapted from Montmessin et al. 2005, within the current version of the LMD Martian GCM (Forget et al. 1999). The fractionation effect caused by the condensation is taken into account with the calculation of a fractionation factor depending on the temperature, according to the empirical formulation of Lamb et al. 2017. In Rossi et al. (2021)'s study, clouds are produced and evolve according to simplified physics consisting in turning water vapour into ice if any supersaturation of water. In the study presented here, the HDO cycle is upgraded to the last version of the water cycle of the model, including the activation of the radiative effect of clouds and their microphysics (referring to the parametrization of the different processes of formation of the clouds, as nucleation of the ice particles on dust particles, water ice growth, dust scavenging and supersaturation), implemented in the model by Navarro et al. 2014. The calculation of the fractionation has also been improved by implementing the effect of kinetics impacting the condensation process. Indeed, the slower diffusion of the heavier HDO molecule in comparison to that of $\mathrm{H}_{2} \mathrm{O}$ reduces condensation flux, and an expression has been established by Jouzel and Merlivat 1984 to include this effect in the overall fractionation of water isotopologues during condensation into ice.

\section{Results and perspectives}

Our results, on the basis of these recent improvements, will be presented at the conference. 
Reinforcement of the Hadley circulation by the radiative effect of clouds which is now taken into account, as well as the role of nuclei played by dust in the cloud formation, do affect the transport of $\mathrm{HDO}$ and its vertical distribution, which directly impacts the $\mathrm{HDO} / \mathrm{H}_{2} \mathrm{O}$ ratio in the low-to-mid atmosphere (see Figure 1). Kinetics of condensation reduces the fractionation effect whenever saturation occurs and increases with supersaturation, which means mainly at the poles (see Figure 2). Further aspects of this upgraded modelling of the HDO cycle and its sensitivity to different parameters will be explored and presented at the conference. The comparison of the model results with observations from TGO/ACS are presented by Loïc Rossi in session TP16.

For now, the here-presented simulations extend to an altitude of around $120 \mathrm{~km}$, and do not include the parametrizations of the thermosphere (Angelats i Coll et al. 2005, Gonzalez-Galindo et al. 2009), the photochemistry (Lefèvre et al. 2004, 2008) and the escape (Chaufray et al. 2015a), which have been recently extended to deuterated species. The ultimate goal of this work is the development of a complete representation of the deuterium cycle, from its source as HDO in the lower atmosphere, to its photodissociation and escape from the upper atmosphere.

\section{LS 90}

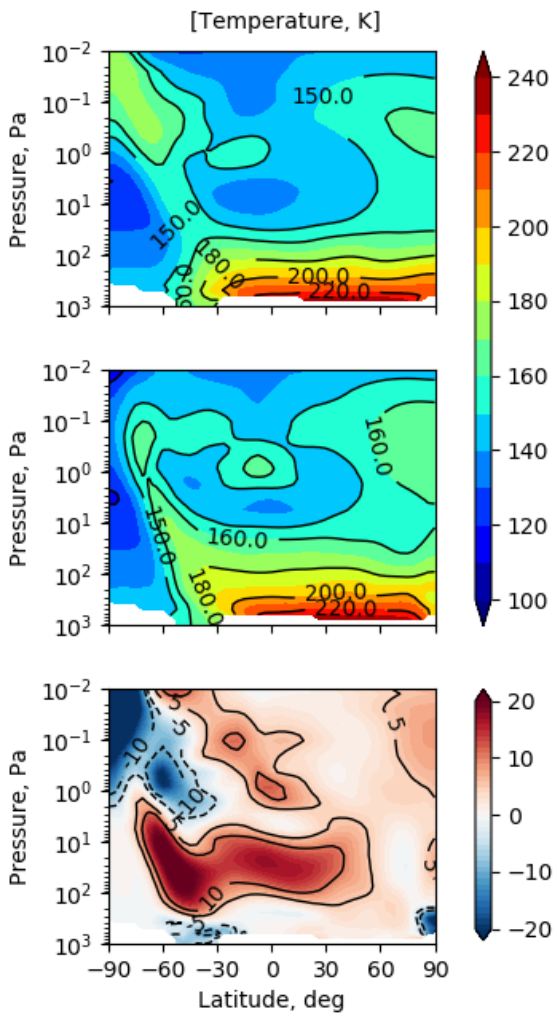

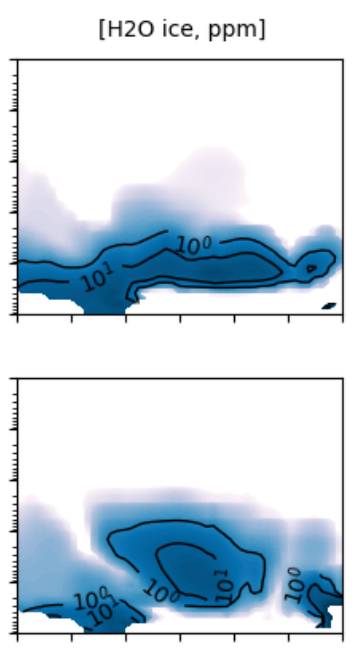

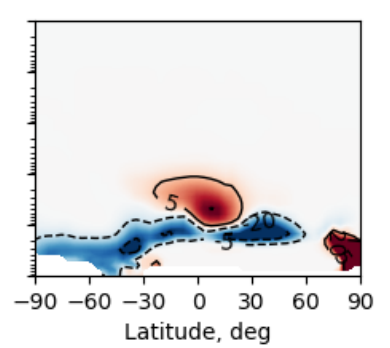

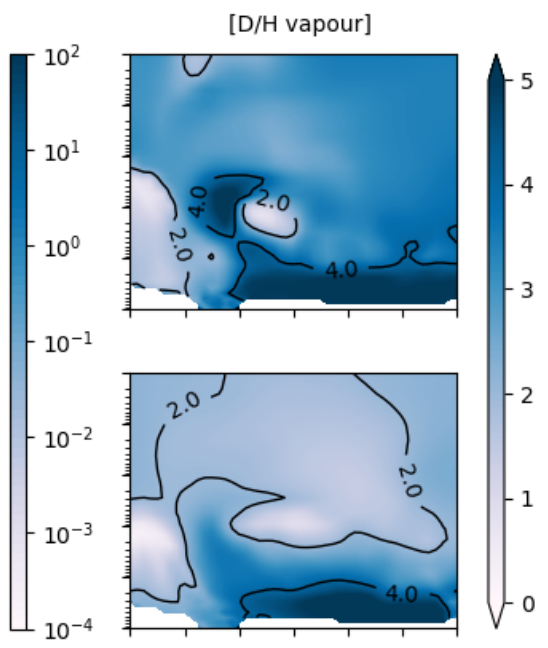

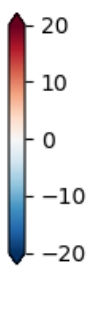

Figure 1: Meteorological variables as output of the model zonally averaged at $L T=14: 00$ around $\mathrm{Ls}=90^{\circ}$. (Up) Results for the GCM simulation run with the simple physics of clouds (1). (Middle) Results for the GCM simulation run with the microphysics and the radiative effect of clouds (2). (Down) Difference between the two simulations (2) - (1). (Left) Temperature (K). (Middle) $\mathrm{H}_{2} \mathrm{O}$ ice mixing ratio (ppm). (Right) $\mathrm{D} / \mathrm{H}$ ratio of the vapour phase. 

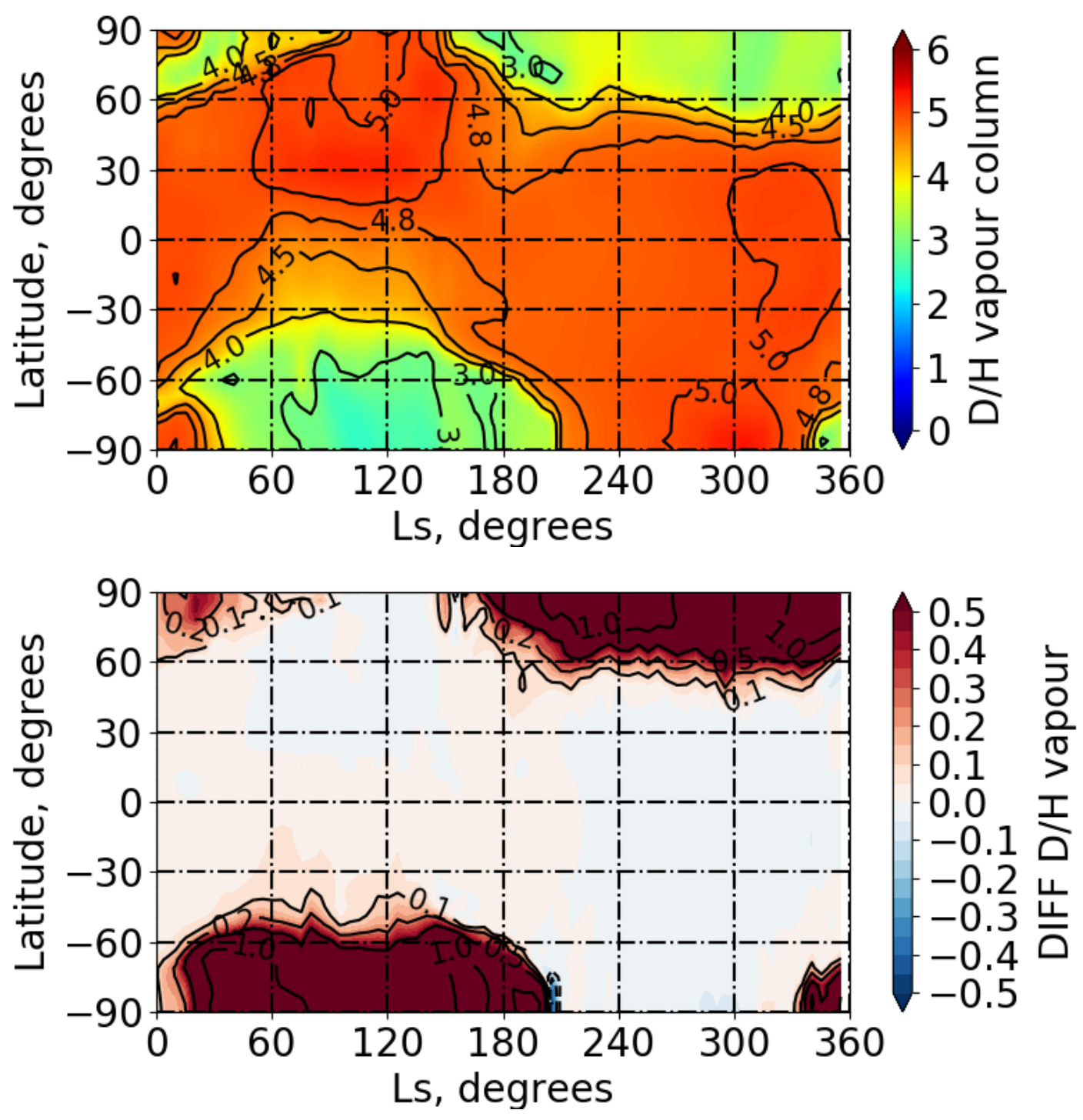

Figure 2: (Left) Zonal average of the integrated column of the $\mathrm{D} / \mathrm{H}$ ratio of the vapour phase for a GCM simulation run with microphysics and radiative effect of clouds, and taking into account the effect of kinetics in the fractionation process. (Right) Difference between simulation with and without taking into account the effect of kinetics.

\section{Acknowledgements}

ExoMars is the space mission of ESA and Roscosmos. The ACS experiment is led by IKI Space Research Institute in Moscow. The project acknowledges funding by Roscosmos and CNES. Science operations of ACS are funded by Roscosmos and ESA. Science support in IKI is funded by Federal agency of science organizations (FANO). M.V. acknowledges support from the DIM ACAV labelled by the Ile-de-France region in support for the research (Domaine d'Intérêt Majeur, Astrophysique et Conditions d'Apparition de la Vie)". 